\title{
Maria do Carmo Vila e a Educação Matemática em Minas Gerais
}

\section{(1970-1995)}

\author{
Maria do Carmo Vila and Mathematics Education in Minas Gerais \\ (1970-1995)
}

\author{
Kelly Maria de Campos Fornero Abreu de Lima Melillo* \\ ORCID iD 0000-0002-5573-1623 \\ Maria Laura Magalhães Gomes** \\ ORCID iD 0000-0003-2423-7750
}

\begin{abstract}
Resumo
Este artigo se insere no âmbito das pesquisas que tratam da participação feminina na História da Educação Matemática. Aborda parte da trajetória profissional da professora Maria do Carmo Vila em Minas Gerais, especialmente no período em que atuou no Colégio Técnico da Universidade Federal de Minas Gerais (UFMG). $\mathrm{O}$ estudo se baseia em depoimentos produzidos com a metodologia da História Oral e documentos coletados em investigação anterior. Focaliza-se o que foi lembrado e contado pela docente e por alguns de seus colegas de trabalho nas décadas de 1970, 1980 e 1990. Os destaques no percurso de Maria do Carmo residem nas suas ações inovadoras na época; na sua formação acadêmica diferenciada, num período em que cursos de Pós-Graduação em Educação Matemática começavam a se disseminar no Brasil; e no seu envolvimento com a formação continuada de professores. Diversas tendências do desenvolvimento da Educação Matemática no Brasil foram notadas nas práticas dessa docente, na época estudada. Evidencia-se que a professora Maria do Carmo se constituiu profissionalmente como importante referência para o ensino de Matemática em Minas Gerais, tendo atuado também em outros estados.
\end{abstract}

Palavras-chave: História da Educação Matemática. Participação Feminina na Educação Matemática. Colégio Técnico da UFMG. História Oral.

\begin{abstract}
This article is part of the research on female participation in the History of Mathematics Education. It focuses on part of the professional trajectory of Professor Maria do Carmo Vila in Minas Gerais, especially during her time at Colégio Técnico, Universidade Federal de Minas Gerais (UFMG). The study is based on interviews according to Oral History methodology and documents collected in a previous research. It deals with what Maria do Carmo and some of her colleagues remembered and told about their teaching practices during the 1970s, 1980s, and 1990s. Maria do Carmo stood out for her innovative actions at the time; for her academic formation, in a period when master and doctorate courses in Mathematics Education began to spread in Brazil; and for her involvement with teacher education. Several trends in the development of Mathematics Education in Brazil were noted in the

\footnotetext{
* Doutora em Educação pela Universidade Federal de Minas Gerais (UFMG). Professora do Setor de Matemática do Colégio Técnico da Universidade Federal de Minas Gerais (Coltec/UFMG), Belo Horizonte, Minas Gerais, Brasil. E-mail: kellyfornero@yahoo.com.br.

** Doutora em Educação pela Universidade Estadual de Campinas (UNICAMP). Bolsista de Produtividade do CNPq. Professora do Departamento de Matemática e do Programa de Pós-Graduação em Educação da Universidade Federal de Minas Gerais (ICEx/UFMG), Belo Horizonte, Minas Gerais, Brasil. E-mail: mlauramgomes@gmail.com.
} 
practices of this teacher from 1970 to 1995. It is evident that Professor Maria do Carmo constituted herself professionally as an important reference for Mathematics teaching in Minas Gerais, as well as in other Brazilian states.

Keywords: History of Mathematics Education. Female Participation in Mathematics Education. Colégio Técnico UFMG. Oral History.

\section{Introdução}

Diversas publicações recentes têm enfatizado a participação feminina na História da Educação Matemática (BRITTIS; GODOY; VIANNA, 2019; CRECCI; NACARATO, 2019; GOMES, 2016; GOMES, 2018; MELILLO; GOMES, 2019; MENEZES, 2019), valorizando substancialmente narrativas em geral e relatos autobiográficos em particular. Enquanto os trabalhos mencionados focalizam personagens específicas nos estados de São Paulo, Minas Gerais e Bahia, fazendo uso de material originado em entrevistas ou biografias escritas, o livro organizado por Valente (2013) é um conjunto de 24 textos dedicados a trajetórias femininas de um número grande de estados brasileiros sem destaque específico para a característica autobiográfica. As mulheres se tornaram a maioria dos docentes no Brasil no Ensino Primário a partir do final do século XIX, no fenômeno conhecido como feminização do magistério, e, gradativamente, a partir dos anos 1930, também passaram a predominar numericamente no Nível Secundário. Levando em conta essa realidade e considerando que a Matemática é tradicionalmente vista como uma carreira masculina, a participação feminina na docência em Matemática é um traço marcante da educação escolar em nosso país que se configura como tema que merece ampliação e aprofundamento nas investigações.

Se mais recentemente tem crescido o número de estudos biográficos/autobiográficos voltados para a participação feminina na História da Educação Matemática, é inegável que muitas pesquisas, durante muito tempo, contemplaram, sobretudo, personagens masculinos de destaque, em virtude de seu predomínio tradicional no magistério e na autoria de livros didáticos ${ }^{1}$ para o Ensino Secundário. No magistério primário, o estudo de Demartini e Antunes (1993) evidenciou que, até as primeiras décadas do século XX, embora as mulheres constituíssem a maioria nas salas de aula, as diretorias e inspetorias escolares, bem como outros cargos técnicos, eram dominados pelos homens. Não conhecemos trabalhos semelhantes a respeito da ocupação de postos semelhantes no Ensino Secundário, mas, considerando-se o longo período antes da existência dos cursos de licenciatura, em que os

\footnotetext{
${ }^{1} \mathrm{O}$ tema da autoria dos livros didáticos de Matemática será retomado adiante neste artigo.
} 
professores de Matemática eram militares ou engenheiros, profissões tradicionalmente masculinas, podemos afirmar que, mesmo depois dos anos 1930, os destaques nos postos de decisão educacional eram geralmente dos homens.

É fundamental considerar também que, mesmo tendo passado a haver cada vez mais mulheres professoras de Matemática e mesmo não havendo barreiras formais para que elas estivessem em tais postos, por longos anos existiram limitações e dificuldades sociais para isso. A presença maior dos homens em alguns cargos importantes relacionados à educação matemática escolar durante um período extenso pode ter contribuído para a produção de pesquisas biográficas/autobiográficas com foco nos educadores matemáticos. Contudo, reiteramos nossa ênfase na existência de um número crescente de trabalhos desse tipo voltados para as educadoras matemáticas.

Pesquisas relacionadas à formação e atuação de docentes que ensinam ou ensinaram Matemática em qualquer nível de ensino com a utilização da metodologia da História Oral têm contribuído para a constituição de um vasto repertório de fontes para esses estudos ao tornarem público o material advindo das entrevistas realizadas, mesmo que o foco da investigação original não esteja nos percursos pessoais dos colaboradores e se situe preferencialmente em espaços institucionais ou regionais. Essa é a perspectiva do presente texto, em que lançamos mão de narrativas colhidas para uma pesquisa (MELILLO, 2018) acerca do ensino de Matemática numa instituição de Ensino Técnico de Belo Horizonte, o Colégio Técnico (Coltec) ${ }^{2}$ da Universidade Federal de Minas Gerais (UFMG), para estudar a trajetória da professora Maria do Carmo Vila, que nela atuou de 1979 a 1995.

A narrativa de Maria do Carmo, assim como as de mais seis docentes de Matemática que também foram colaboradores da investigação ${ }^{3}$, foi conduzida por um roteiro projetado especificamente para construir uma história do Coltec em relação ao ensino de Matemática, de 1969 a 1997. O roteiro da entrevista com professores e professoras da escola foi elaborado de forma a recolher relatos sobre sua formação acadêmica e suas práticas, e continha questões a respeito de sua metodologia de trabalho, recursos empregados e materiais didáticos produzidos e/ou utilizados por eles e elas, motivações pessoais e profissionais, alterações

\footnotetext{
${ }^{2}$ O Coltec foi criado em 1969, a partir de um convênio entre o Conselho Britânico e a UFMG. Seu objetivo era, inicialmente, formar recursos humanos para atuar, especialmente, nos laboratórios de pesquisa da universidade, impulsionando o desenvolvimento científico. Os estudantes eram selecionados por avaliações escritas e, desde o princípio, havia distinção entre os candidatos, que competiam em uma mesma classe socioeconômica. Na sua criação, o Coltec oferecia quatro cursos técnicos. Esses se mantiveram, com atualizações nos currículos e nomes. Atualmente, o Colégio oferece os cursos técnicos de Análises Clínicas, Automação Industrial, de Eletrônica, de Química e, mais recentemente, de Desenvolvimento de Sistemas.

${ }^{3}$ Foram também entrevistados um ex-diretor da escola e oito ex-alunos.
} 
curriculares na escola, permanências, mudanças ou rupturas ocorridas nas práticas pedagógicas em Matemática no Coltec nos anos em que lá atuaram. As entrevistas, portanto, não tinham como foco as histórias de vida dos docentes.

Documentos primordiais para uma investigação anterior sobre o Coltec no período 1969-1997, as entrevistas e os textos dela originados representam registros dos modos como as pessoas ouvidas se viam, viviam e atuavam profissionalmente em dado período e lugar e, por isso, constituem fontes historiográficas (GARNICA; VIANNA, 2019). É possível, portanto, após o trabalho que gerou as narrativas, assegurados os cuidados e procedimentos quanto aos aspectos éticos, fazer uso dessas fontes para explorar outros temas que eventualmente se sobressaiam.

No presente caso, revisitamos os depoimentos de Maria do Carmo Vila e de alguns outros entrevistados de Melillo (2018) para abordar as contribuições da professora para o ensino e a formação de professores de Matemática durante o período em que esteve vinculada à UFMG, assim como para relacionar alguns dos aspectos de seu percurso profissional e acadêmico aos caminhos percorridos pela Educação Matemática brasileira durante as décadas de 1970 a 1990. Entendemos que qualquer narrativa está sempre inserida num contexto sóciohistórico. Assim, uma voz específica em um relato é compreendida por nós em um cenário mais amplo. Por isso, consideramos a narrativa de Maria do Carmo e as de outros docentes que se referem a essa professora dentro da mesma pesquisa como integrantes de todo um sistema de referências: Colégio Técnico, UFMG, ensino de Matemática, abordagens pedagógicas da Matemática, Belo Horizonte, Minas Gerais e Brasil no período coberto pela investigação de Melillo (2018).

Maria do Carmo graduou-se em Licenciatura em Matemática na cidade de Guaxupé/MG, no ano de 1969. Assim que se formou, iniciou a carreira docente na sua cidade natal, Guaranésia, em Minas Gerais, na rede estadual de ensino, lecionando para turmas de quinta à oitava série do nível então denominado Ensino de Primeiro Grau. Em 1970, foi selecionada para um curso que preparava docentes para lecionar nos novos colégios construídos pelo Programa de Expansão e Melhoria do Ensino - Premen e passou a residir na capital mineira. Esse foi o começo de sua trajetória profissional. A partir de então, Maria do Carmo atuaria em diferentes níveis e modalidades de ensino, como será comentado adiante.

Inicialmente, expomos brevemente as bases teórico-metodológicas em que nos apoiamos. A parte central do texto, em seguida, trata da trajetória da professora Maria do Carmo em relação com o desenvolvimento da Educação Matemática como campo profisssional de ensino e pesquisa em Minas Gerais no período 1970-1995. Algumas considerações sobre a 
trajetória da professora Maria do Carmo revelada nas narrativas encerram o artigo.

\section{Fundamentos teórico-metodológicos}

As narrativas usadas neste texto resultam de um trabalho baseado na metodologia da História Oral, conforme princípios e procedimentos essenciais largamente disseminados em produções do Grupo de História Oral e Educação Matemática (Ghoem), tais como Garnica, Fernandes e Silva (2011), Garnica e Martins-Salandim (2016) e Garnica e Vianna (2019). Para situar o leitor, faremos aqui algumas considerações em relação a esses aspectos teóricometodológicos a partir desses e de outros trabalhos voltados para a História Oral.

A História Oral tem seus alicerces na realização de entrevistas e produção de narrativas veiculadas de várias maneiras que, como foi comentado antes, convertem-se em fontes historiográficas. Gravam-se as falas de pessoas que testemunharam ou participaram de acontecimentos do passado ou da época de realização da entrevista, cujo conteúdo trata dos temas de interesse do pesquisador para os quais se considera que o colaborador pode contribuir.

$\mathrm{Na}$ pesquisa que gerou as narrativas envolvidas neste texto, foram feitas gravações em áudio e suas transcrições. Posteriormente, foram produzidas textualizações das entrevistas, isto é, versões das transcrições em que as falas foram reordenadas e a linguagem usada pelos entrevistados foi em parte modificada com o objetivo de suavizar as marcas da oralidade e obter um texto de leitura mais fluente, procurando, entretanto, preservar o teor do que foi dito. As textualizações foram autorizadas pelos colaboradores, que, eventualmente, propuseram mudanças no material até que foi obtida a forma final que integra o trabalho de Melillo (2018). Esses são os textos que relemos e analisamos para a escrita do presente artigo e que designamos como narrativas de Maria do Carmo e de outros professores que lecionaram no Coltec-UFMG.

Nos relatos dos colaboradores de pesquisas que fazem uso da História Oral, eles e elas falam de suas memórias; é, assim, imperioso considerar que o passado é sempre lembrado a partir do presente e aquilo que é narrado é ressignificado no momento da rememoração. $\mathrm{Na}$ História Oral, o passado é repensado, recriado, reelaborado, recontado, com as imagens e ideias do momento da entrevista. Constituindo-se como uma reflexão autobiográfica, cada narrativa é resultado de uma escolha realizada nesse momento. Soares (2001, p. 40), em texto autobiográfico, comenta:

A própria relação daquilo que incluo na narração obedece a critérios do presente: 
escolho aquilo que tenha relações com o sistema de referências que me dirige. A (re)construção de meu passado é seletiva; faço-a a partir do presente, pois é este que me aponta o que é importante e o que não é; não descrevo, pois, interpreto.

A situação de entrevista é condição essencial a ser considerada: afinal, o que se produz está ligado não somente à disposição do entrevistado para discorrer sobre aquelas questões que lhe são propostas, mas, também e fundamentalmente, à interação entre ele e o entrevistador. Alberti (2010) alerta que, na relação de entrevista, aquilo que se diz depende sempre de a quem se diz. Como pondera Bruner (2014, p. 34), uma narrativa é comunicada de uma pessoa a outra; é uma elocução que "tem um propósito específico: o que o narrador pretendia ao fazer esta narração a este espectador desta forma". Contudo, Patai (2010), ao chamar a atenção para a importância do entrevistador, não lhe concede o papel de principal responsável pela entrevista, já que essa visão "não reconhece a autoridade e a criatividade do narrador ao tecer seu próprio texto" (PATAI, 2010, p. 31).

Durante muito tempo, a História Oral foi criticada em relação ao que comumente é referido como "distorções da memória", com alusões frequentes à impossibilidade de se confiar nos relatos dos entrevistados em decorrência da subjetividade. Patai (2010) menciona essas restrições e responde de forma incisiva ao argumento de que a História Oral não se dedica "a checar a veracidade ou a falsidade do que é contado", enfatizando que "não há mentiras em história oral" (PATAI, 2010, p. 121). A autora explica que o narrador constrói o que deseja apresentar ao mundo, independentemente da analogia com os fatos objetivos da vida. Seu autorretrato é, nesse sentido, efetivamente verdadeiro por exprimir verdadeiramente o "eu" que oferece ao mundo.

Garnica e Vianna (2019) salientam que os pesquisadores que trabalham com a metodologia reconhecem, de partida, que não existe memória única e definitiva.

\footnotetext{
Eles sabem que o choque entre diferentes pontos de vista gera várias explicações possíveis para cada acontecimento e são responsáveis por admitir que todas as fontes não podem abranger todos os pontos de vista possíveis e sempre fornecerão uma noção parcial dos acontecimentos, situações ou realidades que desejam explicar ou entender. Pesquisadores que usam história oral sabem - e devem estar preparados para defender esta opção - que as fontes que constroem são únicas e parciais (GARNICA; VIANNA, 2019, p. 2).
}

A memória humana trabalha e retrabalha constantemente as experiências pessoais. Em vez de uma recuperação exata do passado, a rememoração e sua exteriorização escrita ou oral é composta de recortes, seleções, construções, em que a imaginação interfere decisivamente a partir dos interesses, desejos e possibilidades do presente. Haveria especificidades da memória feminina e da masculina? Refletindo acerca das mulheres, Catani et al. (2000) afirmam que existe consenso quanto ao vínculo intrínseco entre sua memória, o lugar que a 
mulher ocupa e os papéis que ela desempenha no espaço social. Se, aparentemente, as mulheres têm lembranças diferentes das dos homens, a diferença não se deve a fatores biológicos, mas aos lugares sociais que ambos ocupam ou ocuparam. A memória é marcada, para homens e mulheres, pelos tipos de papéis sociais desempenhados, em trajetórias constituídas pelo meio socioeconômico e cultural, pelo nível educacional, pela faixa etária, entre outros elementos. Assim, as memórias não são femininas ou masculinas especificamente: elas resultam das experiências de cada pessoa.

Tendo em conta as perspectivas recém-comentadas, passamos, na próxima seção, a discorrer sobre aspectos de destaque na trajetória de Maria do Carmo Vila na Educação Matemática em Minas Gerais no período 1970-1995. O marco inicial refere-se à sua vinda da cidade de Guaranésia, no interior do estado, para a capital, Belo Horizonte, enquanto o final assinala sua aposentadoria no Colégio Técnico da UFMG.

\section{O percurso de Maria do Carmo e a Educação Matemática em Minas Gerais}

Ao nos referirmos ao destaque de Maria do Carmo Vila na Educação Matemática em Minas Gerais, falamos da Educação Matemática como campo profissional de ensino e pesquisa, conforme Fiorentini e Lorenzato (2007). A Educação Matemática, ao estudar o ensino e aprendizagem dos conhecimentos matemáticos, envolve não somente esses conhecimentos, mas essencialmente está associada ao "domínio de ideias e processos pedagógicos relativos à transmissão/assimilação e/ou à apropriação/construção do saber matemático escolar" (FIORENTINI; LORENZATO, 2007, p. 5). Ainda segundo esses autores, concebemos a Educação Matemática como resultante das relações estabelecidas entre o específico e o pedagógico, com múltiplas dimensões como as histórico-epistemológicas, psicocognitivas, sociopolíticas e histórico-culturais.

No período coberto neste estudo, Maria do Carmo viveu e atuou em ambientes diversos, vinculados a diferentes diretrizes educacionais e profissionais. Investigar as narrativas da professora Maria do Carmo, bem como documentos, fotografias e relatos de outras pessoas, empregando a metodologia da História Oral, permitiu-nos não somente entender individualmente a profissional estudada, mas auxiliou-nos na compreensão do contexto do ensino de Matemática no Estado de Minas Gerais, nas décadas de 1970, 1980 e 1990, como se poderá notar no decorrer dos comentários que faremos acerca de sua trajetória.

Ao mudar-se para Belo Horizonte para atuar no Premen, a então jovem professora Maria do Carmo, já graduada, conheceu e trabalhou com professores de Matemática mais 
experientes que atuavam na UFMG: Reginaldo Naves de Souza Lima ${ }^{4}$, Alceu dos Santos Mazzieiro e Antônio David Sobrinho. Os dois últimos haviam lecionado no Colégio Universitário $^{5}$ da UFMG, implantado em 1965, que oferecia apenas o último ano do curso colegial. O contato com Reginaldo, Alceu ${ }^{6}$ e David $^{7}$ possibilitou a Maria do Carmo ingressar na atividade de autoria de materiais didáticos, como explicou em sua entrevista a Melillo $(2018)^{8}$.

Vou contar um pouco mais sobre a minha ligação com o professor Reginaldo. Eu o conheci durante o meu curso do Premen. Depois convivi com ele no Colégio Universitário, quando trabalhávamos eu, ele, Alceu e o David. Nesse período, eu ajudava nas salas de aula e tive a oportunidade de conversar muito com o Reginaldo. Quando eu ainda estava no Colégio Universitário, o professor Reginaldo veio até mim e disse: "olha, eu estou fazendo um livro com o David e o Alceu, mas eu estou pensando em me desvincular, porque eles estão com uma concepção e eu estou com outra. Você quer trabalhar comigo?". Eu aceitei e começamos a escrever os livros de $5^{a}$ série, que hoje seriam os livros de $6^{\circ}$ ano. [...] Reginaldo disse: "Está ótimo, está bom!". Nós discutimos algumas partes, mudamos um pouco e começamos a publicar os livros de $5^{a}$ a $8^{a}$ série. Professores do Premen, inclusive, adotaram esses livros (Textualização da entrevista com Maria do Carmo Vila, 04/05/2016).

Embora mulheres tenham escrito livros didáticos para o ensino da Matemática para os anos iniciais da escolarização no Brasil desde, pelo menos, a década de 1930 (ALMEIDA; LEME DA SILVA, 2014), a participação feminina na autoria de materiais didáticos para os níveis de ensino posteriores, embora existisse, não era muito comum. Alves (2005) apresenta uma lista de livros para o curso ginasial no período 1943-1995 na qual Maria do Carmo Vila é um dos poucos nomes de mulheres mencionados entre os autores. Nesse levantamento, no período 1943-1960, não há qualquer nome de autora entre as obras; de 1960 a 1980, além de Maria do Carmo, figuram apenas Lucília Bechara Sanchez e Manhucia Liberman. De 1980 a 1995, somente um nome feminino aparece na mesma relação, o de Vilma de Moura Rangel Ney.

Outra evidência da pequena presença das mulheres entre as autoras de livros didáticos

\footnotetext{
${ }^{4}$ Reginaldo Naves de Souza Lima dedicou-se ao estudo e à criação de novas propostas de aprendizagem de Matemática e trabalhou como docente na UFMG. Participou da elaboração da proposta curricular de Matemática para o ensino de $1^{\circ}$ grau de Minas Gerais editada em 1993.

${ }_{5}^{5}$ Diferentemente dos cursos pré-vestibulares existentes na UFMG, tratava-se de uma "experiência pedagógica que permitiria o amadurecimento do aluno, sua maior consciência da realidade nacional e regional, preparando-o para realizar o curso superior em melhores condições de desenvolvimento (intelectual, social, cultural)" (COLLARES, 1989, p. 172).

6 Alceu dos Santos Mazzieiro foi professor do Colégio Universitário e do Departamento de Matemática do Instituto de Ciências Exatas da UFMG e teve diversas participações em projetos de capacitação de professores de Matemática da rede estadual de Minas Gerais.

${ }^{7}$ O professor David (1927-2016) ingressou na UFMG no final dos anos 1960, no então Colégio Universitário, e depois se transferiu para o Departamento de Matemática do ICEx, onde permaneceu até se aposentar, no fim dos anos 1990.

${ }^{8}$ Em todo o artigo, os trechos em itálicos são passagens das textualizações de entrevistas concedidas para a pesquisa de Melillo (2018).
} 
de Matemática para as séries finais do $1^{\circ}$ grau (depois denominado Ensino Fundamental) está no Guia do Programa Nacional do Livro Didático (PNLD) de $5^{\mathrm{a}}$ a $8^{\mathrm{a}}$ séries de 1999 (BRASIL, 1999), no qual é imediato verificar a presença majoritária de autores do sexo masculino. O Guia do PNLD1996-1997 (BRASIL, 1997), por outro lado, mostra a presença de um número significativo de autoras de obras para o ensino de Matemática nas quatro séries iniciais do $1^{\circ}$ grau/Ensino Fundamental. A parceria entre Maria do Carmo e Reginaldo Naves de Souza Lima pode ser considerada uma associação pioneira entre homens e mulheres para a escrita de um livro didático de Matemática para os quatro anos finais do então $1^{\circ}$ grau, uma vez que Alves (2005) registra livros da dupla publicados em 1973-1974. Avaliamos que esse tipo de trabalho conjunto pode ter contribuído para que, depois, mais mulheres passassem a escrever e publicar livros didáticos, algumas vezes em grupos exclusivamente femininos.

Em 1973, Maria do Carmo foi aprovada em um concurso para professora da UFMG, para atuar no Departamento de Matemática do Instituto de Ciências Exatas-ICEx. Em agosto de 1975, solicitou licença "para frequentar um curso de Geometria e Álgebra do GEEM" (Grupo de Estudos do Ensino de Matemática de São Paulo) ${ }^{9}$. Posteriormente, no ano de 1978, ela foi convidada para cursar o Mestrado Profissional, orientada pelo coordenador do programa, professor Ubiratan D'Ambrosio. Tratava-se de um curso experimental de mestrado em ensino de Ciências e Matemática, que vigorou de 1975 a 1984 e tinha por objetivo

desenvolver/qualificar especialistas e lideranças em ensino e ciências e matemática, nas diversas regiões da América Latina, que fossem capazes de: promover cursos e programas de melhoria de ensino; desenvolver análise, adaptação e elaboração de currículos; adaptar e produzir material institucional etc. (FIORENTINI; LORENZATO, 2007 p. 23).

Esse curso, de duração temporária, resultava do estabelecimento de um convênio entre a instituição que o sediou, a Universidade Estadual de Campinas (Unicamp), o Ministério da Educação (MEC), a Organização dos Estados Americanos (OEA) e o Premen, tendo formado quatro turmas de professores-estudantes de vários países da América Latina (FIORENTINI; LORENZATO, 2007). Maria do Carmo relatou ter passado um ano em Campinas para cursar as disciplinas e ter voltado a Belo Horizonte para escrever sua dissertação. Ela destacou que se tratava de uma experiência nova, que teve seus percalços:

Naquele tempo, não tinha internet, não tinha recursos, não tinha nada. Não tinha a área da Educação Matemática, realizar pesquisa era muito difícil. Quando eu terminei o meu trabalho, eu o enviei para o Ubiratan e ele disse: "Então, vem defender!" (Textualização da entrevista com Maria do Carmo Vila, 04/05/2016).

\footnotetext{
${ }^{9}$ Informação extraída do Livro de Atas das Reuniões da Câmara do Departamento de Matemática, em que o Chefe do Departamento de Matemática, Jeblin Antônio Abraão, comunicou aos membros da Câmara ter concedido, ad-referendum da Câmara, licença para Maria do Carmo ausentar-se.
} 
A dissertação da professora, "Um modelo de metodologia operatória como alternativa para a melhoria do ensino de Matemática nas séries iniciais do $1^{\circ}$ grau", assim como os demais 27 trabalhos do Programa que integrava, contemplou a orientação geral no sentido de ser uma investigação necessariamente desenvolvida no local de trabalho de cada mestrando (FIORENTINI; LORENZATO, 2007).

Durante o período em que cursou o mestrado, Maria do Carmo conseguiu licença das atividades na Universidade. Ao que parece, o processo não foi simples e imediato. Inicialmente, como ela contou, o Departamento de Matemática, em que era lotada, indeferiu o seu pedido de afastamento, com duração de um ano, com o objetivo de frequentar as aulas em Campinas (SP).

É importante contar que eu lecionava no ICEx quando fui aprovada no mestrado. Nessa ocasião, eu solicitei afastamento por um ano, para ir para a Unicamp, e o meu pedido foi indeferido. Segundo eles, o meu mestrado, em ensino de Matemática, não era prioridade do departamento, não tinha nada a ver. Curiosamente, no mesmo ano, outro docente conseguiu licença para cursar pós-graduação na área de Administração ou Economia (Textualização da entrevista com Maria do Carmo Vila, 04/05/2016).

Segundo Maria do Carmo, seu pedido de afastamento foi concedido posteriormente, com a ajuda da então diretora de outra unidade universitária da UFMG, a Faculdade de Educação. Em contrapartida, ela aceitou a condição proposta pela diretora de, após seu retorno, atuar nas escolas de $1^{\circ}$ e $2^{\circ}$ graus da UFMG.

Quando retornou de seu afastamento, em 1979, foi indicada para atuar no Colégio Técnico, e o pedido da diretoria da escola foi atendido pelo Departamento de Matemática do ICEx. Como docente do Coltec, Maria do Carmo também auxiliava o Departamento de Matemática do Centro Pedagógico ${ }^{10}$, trabalhando na produção de materiais de ensino com o professor Reginaldo. Maria do Carmo relatou seu afastamento do Colégio para a realização do doutorado alguns anos depois:

Até que, em 1988, eu fui para o Canadá fazer o curso de doutorado, na Universidade Laval, uma das mais antigas daquele país. Naquela universidade canadense, não havia a expressão "Educação Matemática", mas "Didática da Matemática". Possivelmente, isso é fruto da colonização francesa (Textualização da entrevista com Maria do Carmo Vila, 04/05/2016).

Sua tese, intitulada "Conceptions manifestées par les élèves dans une épreuve de simulation d'une situation aléatoire réalisée au moyen dún matériel cconcret" foi defendida em 1993, sob a orientação de Claude Gaulin. Nas palavras de Maria do Carmo:

${ }^{10} \mathrm{O}$ Centro Pedagógico é a escola que oferecia, naquela época, o ensino de $1^{\circ}$ grau na UFMG. Essa escola teve origem no antigo Colégio de Aplicação da universidade, fundado em 1954 e transformado em Centro Pedagógico em 1968, a partir da Reforma Universitária. 
Em minha pesquisa de doutorado, eu trabalhei com "Simulação". Então, por exemplo, quando os alunos lançam moedas, ou dados, eles podem descobrir as probabilidades da face superior da moeda ser cara ou coroa, ou da face superior do dado ser 1, 2, 3, 4, 5 ou 6. Eu trabalhei a partir de determinadas situações, em que era possível simular as probabilidades de um certo evento ocorrer. Havia um projeto maior na Universidade, sobre Probabilidade e Estatística, do qual meu orientador e eu participávamos (Textualização da entrevista com Maria do Carmo Vila, 04/05/2016).

Os estudos desenvolvidos por Maria do Carmo no mestrado e posteriormente no doutorado possibilitaram que novos modos de ver e conceber o ensino de Matemática fossem, depois de 1979 e até sua aposentadoria, constantemente introduzidos no Coltec. Airton Carrião, professor do Colégio que ingressou nessa escola em 1992, trabalhou muito próximo a Maria do Carmo e, referindo-se às atividades no Coltec, relatou-nos:

Desde que eu estou aqui, antes eu não sei, sempre teve alguém no setor que era ligado à Educação Matemática, ou seja, estava antenado com o que estava acontecendo. Inicialmente, era a Maria do Carmo, depois passou a ser eu. Nós sempre estivemos lendo coisas novas e tal. Com isso, ao lermos pesquisas, nos colocamos na fronteira. Dessa forma, antes de as coisas virarem moda na maioria das escolas, a gente já conhecia, já havia experimentado. Nesse sentido, a gente andava um pouco na frente, porque sempre tinha alguém aqui que estava antenado no que havia de mais moderno. Então, quando a Maria do Carmo Vila chega do Canadá, ela fala de práticas de ensino que as pessoas aqui nunca tinham ouvido falar, nem haviam pensado a respeito (Textualização da entrevista com Airton Carrião Machado, 08/03/2016).

Esse movimento de implementar o que era realizado e discutido fora do Estado e do país, reproduzindo métodos e propostas de ensino que não estavam pré-definidos nos currículos e bibliografias daquele período, trazidos de sua formação complementar, em Campinas, no estado de São Paulo, e em Quebec, no Canadá, aliado ao interesse de Maria do Carmo em produzir materiais para o ensino com autonomia e protagonismo no processo, pode ser visto como característico da insubordinação criativa. Esse conceito foi trazido ao contexto brasileiro pelas autoras Beatriz Silva D’Ambrosio e Celi Espasandin Lopes e foi aplicado a profissionais da educação, entre eles docentes, como explicitado a seguir:

\footnotetext{
cada professor é único, e define suas práticas com base em traços de personalidade, sentimentos, crenças e expectativas. Quando movidos para melhorar a aprendizagem dos alunos e investir na melhoria das condições em que essa aprendizagem ocorre, os professores criam e colocam padrões de movimento e procedimentos que estão alinhados com a sua identidade profissional. Essas atitudes são de forma responsavelmente subversiva e resultam em atos de insubordinação criativa (LOPES; D’AMBROSIO; CORRÊA, 2016, p. 288).
}

Maria do Carmo tinha um fazer especial e autônomo que, a nosso ver, configurava uma postura de insubordinação criativa. Aparentemente, essas atitudes encantavam o professor Airton:

Para mim, era tudo fantástico, eu adorava ficar conversando com ela. Eu ficava parado ouvindo e pensando: "Eu estou aprendendo tanto com ela". Quanto mais ela vinha conversar 
comigo, mais eu gostava, porque eu aprendia muito. Algumas das coisas que ela me falava eu falava: "Gente, não vai ter jeito de isso dar certo". E, depois, com o tempo, quase tudo que ela veio falar comigo, no começo dos anos 90, hoje são coisas rotineiras (Textualização da entrevista com Airton Carrião Machado, 08/03/2016).

A fala de outro ex-docente, Luiz Humberto, que atuou na escola de 1970 a 1991, também traz indicadores da insubordinação criativa da mineira Maria do Carmo, como podemos constatar no trecho a seguir.

Vamos abrir um parêntesis para eu falar sobre os professores Reginaldo e Maria do Carmo. Os dois formavam um grupo para modificar o conteúdo matemático. Não me refiro somente à forma de ensinar, mas ao conteúdo mesmo. Eles criaram a Matemática Moderna, que gerou uma certa resistência da turma das Ciências Exatas, a turma da Matemática. Reginaldo e Maria do Carmo se inspiravam na Matemática Moderna, proposta por um francês, do qual não me lembro o nome. A Matemática por eles ensinada era inteiramente diferente da Matemática Clássica, a abordagem do conteúdo também era diferente. Essa Matemática Moderna não tinha formalidade, não obedecia um currículo. Além disso, priorizava o trabalho com materiais concretos. A criação desse grupo de trabalho, que difundia a Matemática Moderna, não era aceita por alguns matemáticos, que queriam manter a forma tradicional. Esse grupo vigorou por algum tempo, mas não sei contar qual foi o desfecho dele (Textualização da entrevista com Luiz Humberto Pinheiro, 02/03/2016).

Percebemos claramente que Luiz Humberto, muitos anos depois de sua convivência com Maria do Carmo e Reginaldo, chamou de Matemática Moderna a algumas características que associava à atuação da professora no Coltec. Contudo, embora traços do movimento modernista difundido no Brasil a partir dos anos 1960 possam ser identificados na fala do professor, observamos que ela também envolve outros aspectos do trabalho de Maria do Carmo, particularmente as mudanças implementadas pela docente quando ingressou no Colégio.

Sua transferência do Departamento de Matemática do ICEx para o Coltec, inclusive, esteve vinculada à expectativa de melhorias no Setor de Matemática do Colégio, como está registrado no Livro de Atas das Reuniões da Câmara do Departamento de Matemática do ICEx, em 21 de março de 1977: "Pedido do Diretor do Coltec para que Maria do Carmo fosse colocada à disposição do Colégio para participar de projeto de reforma do programa de Matemática”. A ata atesta que o pedido foi aprovado por unanimidade pelos membros da Câmara.

Em conformidade com a ideia de Maria do Carmo como uma presença inovadora destacada no Colégio, a pesquisa realizada por Melillo (2018) oferece alicerces para afirmarmos que as práticas de ensino desenvolvidas pela docente iam ao encontro das discussões, tendências e concepções de ensino de Matemática difundidas no país naquele período. Como exemplo relevante, destacamos o uso, pela professora, dos recursos metodológicos denominados Instruções Programadas e Estudos Dirigidos, nas décadas de 
1960 e 1970 (MELILLO; GOMES, 2019).

Fiorentini (1994) pesquisou os poucos estudos investigativos sobre o ensino de Matemática no Brasil, antes da década de 1970, e analisou 204 teses/dissertações produzidas/defendidas no país na década de 1970. Ele observou, inicialmente, que quase $20 \%$ dessas investigações tinham como objetivo averiguar "os métodos e técnicas de ensino de Matemática" (FIORENTINI, 1994, p. 185). Em seguida, considerando apenas a década de 1970, o autor constatou que $25 \%$ dos trabalhos tinham esse foco temático. A maioria deles referia-se ao ensino individualizado ou à Instrução Programada, além de outros métodos de ensino e aprendizagem. Notemos que, nesse período, o Coltec iniciou o seu funcionamento, com forte adesão aos Estudos Dirigidos e Instruções Programadas, com a participação de Maria do Carmo, juntamente com outros professores (MELILLO, 2018).

Na década de 1980, a pesquisa de Fiorentini (1994) mostrou que o número de trabalhos que abordam o ensino individualizado (sobretudo a instrução programada) não representava 3\% do total produzido. Entretanto, quando o professor Airton passou a lecionar no Coltec, em 1992, ainda observou o emprego dessa metodologia. De acordo com ele, em grande parte do tempo, os alunos

gostavam do ensino de Matemática do Coltec e tinham um bom desempenho nas provas de vestibular. Mas teve uma época em que os estudantes reclamavam muito, muito mesmo. [...] Eles se queixavam de ficarem muito soltos, de não entenderem a proposta. Relatam que tiveram que estudar sozinhos, pois alguns professores vinham, passavam as atividades e não participavam de nada, não sistematizavam. Então, eu ouvia muita reclamação (Textualização da entrevista com Airton Carrião Machado, 08/03/2016).

A permanência das Instruções Programadas e dos Estudos Dirigidos por um longo período não afastou a inserção de recursos complementares na escola. Desde seu contato com o doutorado, iniciado em 1988, Maria do Carmo incentivava, no Setor de Matemática do Coltec, a proposta de Resolução de Problemas. Além disso, passou a fazer uso de outras metodologias, como a Modelagem Matemática, recém-introduzida no país, como contou:

eu sempre fiz o que o pessoal trabalha hoje em dia com o nome de "Modelagem Matemática". Você parte de uma situação e "matematiza", você encontra uma fórmula. Você pode utilizar modelagem até com as crianças. Eu uso isso até hoje. Trabalho com padrões da Física, da Química, da natureza, em geral. A partir de exemplos, podemos retirar padrões, leis. Ao fazer isso, você está trabalhando modelagem (Textualização da entrevista com Maria do Carmo Vila, 04/05/2016).

Concomitantemente, outros métodos e técnicas de ensino passaram a figurar nas investigações acadêmicas. Resolução de Problemas e Modelagem Matemática (ou uso de modelos matemáticos no ensino) totalizaram $12 \%$ das produções dos últimos quatro anos da década de 1980 (FIORENTINI, 1994). 
Esse fazer da professora Maria do Carmo, que pode ser considerado inovador quando se pensa nas práticas usuais na maior parte das escolas da época, ligado a suas experiências e trocas na Universidade e no Coltec, bem como sua formação acadêmica de destaque por ter cursado mestrado e doutorado quando a Pós-Graduação ainda não era tão disseminada como atualmente, impulsionou trabalhos de capacitação e treinamento de professores, como clarificou a docente em seu testemunho:

Os materiais desenvolvidos para trabalhar no Coltec e, principalmente, no Centro Pedagógico, eram usados nos cursos de capacitação de professores em Minas Gerais e em outros estados: Mato Grosso, Rondônia, Paraná, .... Nós produzíamos material e mandávamos de ônibus, especialmente eu e o Reginaldo, juntamente ao Cecimig ${ }^{11}$ (Textualização da entrevista com Maria do Carmo Vila, 04/05/2016).

Nos documentos dos arquivos do Cecimig, armazenados na Faculdade de Educação da UFMG, encontramos registros da atuação de Maria do Carmo naquele centro que testemunham sua participação em projetos de melhoria do ensino de Ciências e Matemática que envolviam docentes de Minas Gerais, da Bahia e do Paraná em 1973 e 1976.

Essas ações de treinamento e aperfeiçoamento de docentes de $1^{\circ}$ e $2^{\circ}$ grau eram elaboradas a partir dos problemas percebidos por Maria do Carmo e Reginaldo Naves nas salas de aula de Matemática que eles investigavam.

Assim que o material estava pronto, os professores do Centro Pedagógico aplicavam em suas turmas. Dessa forma, nós tínhamos um retorno sobre esse material: "esse ponto aqui está bom", "aqui os meninos tiveram dificuldades". A partir daí, nós fazíamos as revisões necessárias. Em seguida, esse material era enviado para outras cidades ou estados (Textualização da entrevista com Maria do Carmo Vila, 04/05/2016).

Alguns desses trabalhos eram realizados a distância, como ela explicou: "Fizemos também capacitações por meio de 'ensino a distância', na época não se chamava 'educação a distância"'. Ela acrescentou:

Em alguns casos, os professores do Centro Pedagórico e do Coltec iam até os pólos, nos finais de semana, coordenar os cursos de capacitação. Eles distribuíam materiais, trabalhavam os conteúdos e sugeriam propostas de ensino aos docentes da região. Em seguida, de posse dos materiais, os professores em capacitação estudavam sozinhos e aplicavam algumas propostas em suas salas de aula. No encontro seguinte, eles socializavam suas práticas e esclareciam possiveis dúvidas com os coordenadores. A gente discutia ensino, líamos textos sobre Educação. Nós fizemos isso muito tempo. A Tânia do Coltec participou muito dessas capacitações (Textualização da entrevista com Maria do Carmo Vila, 04/05/2016).

A professora Tânia, que atuou no Coltec de 1979 a 2002, lembrou-se de seu trabalho

\footnotetext{
${ }^{11}$ O Centro de Ensino de Ciências e Matemática de Minas Gerais - Cecimig, criado em 1965, através de um convênio entre o MEC e a UFMG, foi incorporado à Faculdade de Educação em 1987. Dentre seus objetivos o centro visa estimular a pesquisa e a extensão, contribuindo para a melhoria do ensino de Ciências. Disponível em: < http://www.cecimig.fae.ufmg.br/index.php/institucional/historia>. Último acesso em: 07 jul. 2016.
} 
no Cecimig, em associação com Maria do Carmo:

no Coltec, além de poder lecionar de forma "diferenciada", eu podia divulgar esse meu trabalho, meus métodos, minha filosofia por este Brasil afora, em cursos de capacitação docente elou congressos de Educação Matemática. [...] Ofereci tantos cursos, que já nem me recordo de todos, seus nomes. Era comum os professores do Coltec oferecerem cursos para professores da Prefeitura, do Estado. A gente assessorava docentes atuantes no $1^{\circ}$ e $2^{\circ}$ Graus. Ensinávamos metodologias de ensino e uso de recursos didáticos, que tinham como proposta motivar os alunos. Os resultados eram evidentes, era notório o sucesso dos alunos. Eles entendiam e aprendiam, de fato, os conteúdos, a partir das nossas propostas de ensino (Textualização da entrevista com Tânia Lima Ayer de Noronha, 16/03/2016).

Nas recordações do professor Airton, mencionado anteriormente, era comum os docentes do Coltec se reunirem no Colégio para preparar cursos de treinamento para outros professores.

Eles se reuniam uma vez por semana, ou uma vez a cada quinze dias, não lembro mais. Eles discutiam propostas de cursos para professores, pois davam muitos cursos. Eles tinham apostilas para o Ensino Fundamental inteiro, com todos os assuntos. A partir desse material, eles davam os cursos, algumas vezes no interior do estado (Textualização da entrevista com Airton Carrião Machado, 08/03/2016).

Além das informações anteriores, encontramos no arquivo do Setor de Matemática do Coltec registros de que a professora Maria do Carmo também atuou no Programa de Expansão e Melhoria da Educação no Meio Rural do Nordeste - Edurural - NE (Decreto ${ }^{\circ}$ 85.287, de 23 de Outubro de 1980), que tinha como objetivo a "expansão das oportunidades educacionais e a melhoria das condições da educação no meio rural do Nordeste, bem como o fortalecimento do processo de planejamento e administração educacionais" ${ }^{12}$. Foram encontradas duas correspondências destinadas à professora Maria do Carmo. A primeira delas convidava-a a participar do Encontro de Potenciadores do Edurural da Bahia (docentes que levariam/multiplicariam os conhecimentos, adquiridos nesse encontro, a outros professores, em diferentes regiões do Estado), na cidade de Salvador, em 1983. No segundo convite, enviado no mesmo ano, ela foi chamada para ministrar aulas de Matemática na III Semana Pedagógica, no Estado do Maranhão, num evento promovido pelo mesmo projeto.

Wielewski, Palaro e Wielewski (2008) comentam uma participação importante dos professores Reginaldo e Maria do Carmo na formação de professores do estado do Mato Grosso no início da década de 1980. O NAEC (Núcleo de Apoio ao Ensino de Ciências) da Universidade Federal de Mato Grosso (UFMT) "soube da existência de uma proposta de Ensino de Matemática desenvolvida pelos professores Reginaldo Naves de Souza Lima e

12 Disponível em: <http://www2.camara.leg.br/legin/fed/decret/1980-1987/decreto-85287-23-outubro-1980434719-publicacaooriginal-1-pe.html>. Último acesso em: 20 out. 2020. 
Maria do Carmo Vila, da Universidade Federal de Minas Gerais (UFMG), redigida na forma de um Material Instrucional de Matemática" (WIELEWSKI; PALARO; WIELEWSKI, 2008, p. 680). Em parceria com a Secretaria Estadual de Educação e Cultura, a UFMT ofereceu cursos ministrados por Maria do Carmo e Reginaldo a professores de Matemática da rede de ensino do estado que utilizaram o referido material ${ }^{13}$.

A participação de Maria do Carmo e outros professores da Universidade e do Coltec em capacitações docentes possibilitava trocas de experiências, que inspiravam outros professores, como ela comentou em sua entrevista: "De certa forma, nós influenciávamos os modos de ensinar de outros docentes, a partir desses cursos" (Textualização da entrevista com Maria do Carmo Vila, 04/05/2016).

Maria do Carmo continuou em atividade intensa na Educação Matemática após sua aposentadoria no Colégio Técnico da UFMG. Participou de diferentes comissões, prestou consultorias e lecionou na Universidade Federal de Ouro Preto-MG (Ufop), nas modalidades presencial (inicialmente) e a distância, em nível de graduação e pós-graduação. A entrevista de Maria do Carmo em foco neste artigo, em maio de 2016, foi realizada em seu gabinete no Centro de Educação Aberta e a Distância (Cead/Ufop).

Ficou claro que, após seu ingresso no Cead, a docente concentrou suas ações em atividades relacionadas ao Ensino a Distância. Além de coordenar esse centro, Maria do Carmo presidiu o colegiado do curso de Licenciatura em Matemática - EaD da Ufop em 2015/2016. Realizou pesquisas e publicações com essa temática e escreveu 12 livros sobre conteúdos matemáticos para o Núcleo de Educação Aberta e a Distância da Universidade Federal de Mato Grosso (Nead/UFMT). A temática do ensino a distância também esteve presente em trabalhos de mestrado e doutorado orientados por Maria do Carmo ${ }^{14}$.

\section{Para concluir: reflexões sobre a trajetória de Maria do Carmo}

Em sua narrativa, Maria do Carmo mostrou muito entusiasmo pelo trabalho que realizou durante o período em que atuou como docente da UFMG, lecionando para os estudantes do Coltec, produzindo diversos materiais didáticos e participando da formação

13 Em seu artigo, Wilewski e seus colegas, além de apresentarem uma descrição detalhada do Material Instrucional, comentam a forte presença de conteúdos propostos pelo movimento da Matemática Moderna nele e em outras publicações de Reginaldo e Maria do Carmo, num período em que o movimento modernista já tinha sido muito criticado no Brasil.

14 Fonte: Currículo Lattes da professora Maria do Carmo Vila. Disponível em:

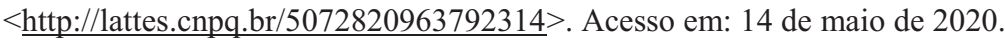


continuada de professores. Ela salientou que os alunos do Coltec eram muito exigidos pelos professores e enfatizou que eram interessados e dedicados aos estudos. Maria do Carmo destacou as repercussões positivas de vários dos materiais que utilizava na escola, descrevendo-os detalhadamente em sua entrevista. Apresentou vários exemplares desses materiais à entrevistadora, demonstrando ter tido cuidado em guardá-los, mesmo mais de vinte anos após sua aposentadoria na UFMG.

Ao falar sobre sua atuação como professora de Matemática, foi visível a ênfase conferida pela professora aos sucessos obtidos quanto à aprendizagem dos estudantes. Desse modo, o depoimento de Maria do Carmo foi constituído, sobretudo, de representações positivas de si própria e do modo como exerceu a profissão. Uma de suas frases, ao se referir ao trabalho desenvolvido junto aos colegas docentes, é ilustrativa de seu sentimento de ter sido responsável por inovações significativas: nós reinventamos a maneira de lecionar Matemática (Textualização da entrevista com Maria do Carmo Vila, 04/05/2016). Por outro lado, é importante dizer que colegas também a retrataram positivamente em suas entrevistas, realçando suas características de liderança, sua postura de abrir caminhos novos no ensino.

Cabe assinalar que ela fez questão de fazer sobressair o apoio que teve de algumas pessoas, particularmente de um professor mais velho e mais experiente, junto a quem atuou por muitos anos - o professor Reginaldo, que conheceu logo que se mudou para Belo Horizonte e a quem esteve ligada em várias situações dentro da UFMG, no Colégio Universitário, no Centro Pedagógico e no Cecimig. Maria do Carmo acentuou o trabalho em conjunto com Reginaldo, apesar de ambos lecionarem em escolas diferentes dentro da universidade, ele no Centro Pedagógico e ela no Colégio Técnico. Em sua entrevista, ela ressaltou muito a produção, em cooperação mútua entre ela e Reginaldo, de materiais sobre tabuadas, jogos de moedas, atividades que envolviam dança e acrobacia e histórias em quadrinhos.

Maria do Carmo também se referiu ao bom ambiente constituído pelos colegas do Coltec como fator relevante para sua satisfação profissional. Mesmo quando falou de um aspecto negativo em sua trajetória - a oposição que encontrou quanto à concessão de licença para afastar-se de Belo Horizonte para o mestrado dentro do Departamento de Matemática, em que esteve lotada inicialmente na UFMG -, a docente acentuou o apoio recebido da professora Ana Maria Casasanta, na época diretora da Faculdade de Educação da mesma universidade, que possibilitou seu afastamento para cursar disciplinas na cidade de Campinas. Portanto, essa retratação positiva de si própria, resultante de sua intenção e sensibilidade no momento de produzir respostas sobre seu passado à entrevistadora, se revestiu do 
reconhecimento a pessoas que contribuíram para suas realizações.

A reconstrução seletiva dos acontecimentos feita pela professora envolveu sua individualidade inserida num contexto social e educacional específico ligado ao desenvolvimento da Educação Matemática no Brasil, no qual se sobressaíram aspectos como os materiais didáticos propostos em algumas épocas, a Pós-Graduação stricto sensu na área, que começava a se disseminar no Brasil, a pesquisa voltada diretamente para a prática pedagógica em Matemática, o trabalho intenso de aperfeiçoamento de professores da rede pública. Um ponto que nos parece fundamental na atuação de Maria do Carmo é a possibilidade que teve de investir seu tempo em todas essas atividades, enquanto trabalhava na UFMG, porque, a partir de certo momento de seu percurso na instituição, passou a ser contratada em dedicação exclusiva. Ela própria reconheceu, na entrevista, a relevância desse regime de trabalho, que lhe possibilitou deixar outras instituições em que lecionava e concentrar-se nas atividades dessa universidade.

Maria do Carmo, que atuou na Educação Básica e Superior, dedicou seu percurso profissional à formação acadêmica, capacitação docente, inovação em ensino e formação de professores. Sua narrativa, bem como as de colegas que a ela se referiram em seus depoimentos, evidencia que ela buscou horizontes mais amplos, que se constituíram como valores incorporados a suas práticas no período investigado na entrevista focalizada. Nas narrativas de e sobre essa mulher, é nítida sua extrema dedicação ao trabalho. Talvez essa seja uma das razões determinantes da ausência de alusões a sua vida pessoal em seu relato: pais, irmãos, escolarização inicial, casamento, filhos, trabalhos domésticos não foram mencionados, o que diferencia seu depoimento do de outros professores e professoras entrevistados na pesquisa de Melillo (2018) e em outros trabalhos.

No entanto, algumas particularidades da vida pessoal de Maria do Carmo surgiram em relatos informais feitos por seus colegas de trabalho, assim como há menções a elas em depoimentos colhidos na ocasião da pesquisa de Melillo (2018). Esses fragmentos sugerem que ela sempre foi muito feliz e realizada. Sua alegria era passar o dia trabalhando, na escola ou em sua residência. Sua situação, de mulher solteira e sem filhos, pareceu circunstancial aos colegas, sem relação direta com sua dedicação à profissão. Quiçá, Maria do Carmo apreciava um ideário feminista de liberdade e autonomia. Vez ou outra, narrava memórias de viagens, uma paixão explicitada. Seu modo reservado e discreto, concentrado nas funções e cargos assumidos, não possibilitava que usualmente comentasse outros aspectos de sua vida privada.

Consideramos, anteriormente, que tanto o entrevistador quanto o entrevistado são extremamente importantes na constituição de uma narrativa. Sublinhamos o papel de 
protagonista do narrador para tecer seus relatos, valorizando também a atuação do entrevistador. A entrevistadora de Maria do Carmo era docente do Coltec desde 2007 e, na ocasião, empreendia uma pesquisa a respeito da escola. Nessa condição, demonstrou, na época, interesse pelo depoimento de Maria do Carmo. Essa circunstância possivelmente deixou ambas à vontade na situação da conversa e pode ter contribuído para que a colaboradora discorresse sobre suas experiências com muita fluência. Dessa forma, na interlocução, as poucas perguntas buscaram apenas dar rumo ou apontar uma ou outra questão específica para esclarecer algum ponto que não estivesse claro. Tendo procurado ouvir o relato de Maria do Carmo com atenção e interesse, a pesquisadora guardava consigo experiências similares às contadas pela docente que havia vivenciado no Colégio Técnico, para comentá-las posteriormente, no final da entrevista, de modo a não interromper a fala e sua sequência cronológica. No trabalho de Melillo (2018, p. 97), consta o seguinte registro da entrevistadora sobre sua impressão imediata após o encontro com Maria do Carmo: "Lembrome que, ao terminar, não tinha noção de quanto tempo havia se passado" (MELILLO, 2018, p. 97).

Cabe sublinhar que a tessitura de uma narrativa de História Oral depende não apenas das características do narrador mobilizadas no momento da entrevista e do tipo de relação estabelecida com o entrevistador. No caso aqui estudado, as questões do roteiro elaborado com vistas à investigação da trajetória do ensino de Matemática no Colégio Técnico contemplavam, sobretudo, temas da profissão dos professores. Ocupar o espaço com aspectos pessoais e familiares, embora tenha ocorrido em algumas das entrevistas da pesquisa, seria ultrapassar o roteiro. Falar desses aspectos sem que estivessem explicitados dependeria das características de cada docente e de como ele ou ela as inseriria durante a entrevista ao discorrer sobre sua experiência no Coltec.

Até meados do século passado, notava-se que os registros de lembranças das mulheres privilegiavam claramente o que se convencionou chamar "esfera do privado" em oposição à “esfera do público". Sem dúvida, foi depois da segunda metade do século XX que as mulheres ocuparam maciçamente posições profissionais e foi desde então que elas se tornaram a maioria. A partir dessa época, no Brasil as mulheres têm participado intensamente do espaço público, exercendo diversificadas responsabilidades sociais e profissionais.

Maria do Carmo foi entrevistada com o objetivo de se investigar a trajetória de ensino de Matemática numa instituição em que atuou durante 16 anos e, assim, seu depoimento foi buscado na esfera do público. Maria do Carmo exerceu o magistério, uma das profissões consideradas adequadas para as mulheres brasileiras desde, pelo menos, o início do século 
XX. Tendo tido e aproveitado oportunidades de formação acadêmica em Matemática e Educação Matemática e trabalhado ativamente como docente e formadora de docentes, sua narrativa autobiográfica com o Coltec como pano de fundo situou-se inteiramente no espaço público de sua atividade profissional.

\section{Referências}

ALBERTI, V. Fontes orais: histórias dentro da história. In: PINSKY, C. P. (org.). Fontes históricas. São Paulo: Contexto, 2010, p. 155-202.

ALMEIDA, D. H.; LEME DA SILVA, M. C. Alfredina de Paiva e Souza e o Instituto de Educação do Rio de Janeiro: a vanguarda da tabuada na era dos testes. Caminhos da Educação Matemática em Revista, Aracaju, v. 1, n. 1, p. 48-70, 2014.

ALVES, A. M. M. Livro didático de Matemática: uma abordagem histórica (1943-1995). 2005. Dissertação (Mestrado em Educação) - Universidade Federal de Pelotas, Pelotas, 2005.

BRASIL. Guia do PNLD de $1^{\text {a a }} 4^{\text {a }}$ séries -1996-1997. Brasília: Ministério da Educação, 1997.

BRASIL. Guia do PNLD de 5a a 8 ${ }^{\text {a }}$ séries-1999. Brasília: Ministério da Educação, 1999.

BRITIS, K. G.; GODOY, E. V.; VIANNA, C. R. Célia Maria Carolino Pires: uma educadora matemática e suas reflexões sobre propostas curriculares. Boletim de Educação Matemática. Bolema, Rio Claro, v. 33, n. 63, p. 411-433, 2019.

BRUNER, J. Fabricando histórias: direito, literatura, vida. São Paulo: Letra e Voz, 2014.

CATANI, D. B; BUENO, B. O.; SOUSA, C. P. de; SOUZA, M. C. C. C. de. História, memória e autobiografia na pesquisa educacional e na formação. In: CATANI, D. B; BUENO, B. O.; SOUSA, C. P.; SOUZA, M. C. C. C. (org.). Docência, memória e gênero: estudos sobre formação. São Paulo: Escrituras, 2000. p. 15-47.

COLLARES, M. M. Colégio de Aplicação da Faculdade de Filosofia de Minas Gerais: A trajetória de uma escola de ensino médio no contexto universitário. 1989. Dissertação (Mestrado em Educação) Faculdade de Educação, Universidade Federal de Minas Gerais, Belo Horizonte, MG, 1989.

CRECCI, V.; NACARATO, A. M. Histórias de Insubordinações Criativas - narrativas de educadoras matemáticas. Bolema, Rio Claro, v. 33, n. 65, p. 1487-1507, 2019.

DEMARTINI, Z. B. F.; ANTUNES, F. F. Magistério: profissão feminina, carreira masculina. Cadernos de Pesquisa, São Paulo, n. 86, p. 5-14, 1993.

FIORENTINI, D. Rumos da Pesquisa Brasileira em Educação Matemática: o caso da produção científica em cursos de Pós-Graduação. 1994. Tese (Doutorado em Metodologia de Ensino) Faculdade de Educação, Universidade Estadual de Campinas, Campinas, 1994.

FIORENTINI, D.; LORENZATO, S. Investigação em Educação Matemática: percursos teóricos e metodológicos. 2. ed. Campinas: Editora Autores Associados, 2007. Coleção Formação de Professores. v. 1.

GARNICA, A. V. M.; FERNANDES, D. N.; SILVA, H. da. Entre a amnésia e a vontade de nada esquecer: notas sobre regimes de historicidade e História Oral. Bolema, Rio Claro, v. 25, n. 41, p. 213 - 
$250,2011$.

GARNICA, A. V. M.; MARTINS-SALANDIM, M. E. História e Educação Matemática: perspectivas e um projeto coletivo. In: RODEGHERO, C. S.; GRINBERG, L.; FROTSCHER, M. (org.). História oral e práticas educacionais. Porto Alegre: Editora da UFRGS, 2016. p. 181-204.

GARNICA, A. V. M.; VIANNA, C. R. Oral History in Mathematics Education: an overview. In: GARNICA, A.V. M. (org.). Oral History and Mathematics Education. New York: Springer, 2019, p. 01-20. v. 1.

GOMES, M. L. M. História da formação de professores que ensinam matemática: no livro de memórias de uma professora paulista. Revista de História da Educação Matemática, v. 2, p. 117$133,2016$.

GOMES, M. L. M. Professoras que ensinaram Matemática: memórias de Maria da Glória, Botyra e Felicidade. Revista de História da Educação Matemática, v. 4, p. 116-138, 2018.

LOPES, C. E; D'AMBROSIO, B. S; CORREAA, S. A. A insubordinação criativa em Educação Matemática promove a ética e a solidariedade. Zetetiké, Campinas, v. 24, n. 3, p. 287-300, 2016.

MELILLO, K. M. C. F. A. de L.; GOMES, M. L. M. Tânia Lima Ayer de Noronha e sua trajetória no Colégio Técnico da UFMG. Revista Brasileira de Pesquisa (Auto)biográfica, v. 4, p. 662-679, 2019.

MELILLO, K. M. C. F. A. L.; GOMES, M. L. M. Livros didáticos e outros materiais escritos no Colégio Técnico da UFMG (1969-1997). Zetetiké, Campinas, v. 27, p. 1-16, 2019.

MELILLO, K. M. F. A. de L. História de práticas de ensinar-aprender Matemática no Colégio Técnico da UFMG-Coltec (1969-1997). 2018. 706f. Tese (Doutorado em Educação) - Faculdade de Educação, Universidade Federal de Minas Gerais, Belo Horizonte, 2018.

MENEZES, M. B. Protagonismo feminino na Matemática: criação e evolução do Instituto de Matemática da Universidade Federal da Bahia. Bolema, Rio Claro, v. 33, n. 65, p. 1067-1086, 2019.

PATAI, D. História oral, feminismo e política. São Paulo: Letra e Voz, 2010.

SOARES, M. Metamemória-memórias: travessia de uma educadora. 2. ed. São Paulo: Cortez, 2001.

VALENTE, W. R. Educadoras matemáticas: memórias, docência e profissão. São Paulo: Editora Livraria da Física, 2013.

WIELEWSKI, G. D.; PALARO, L. A.; WIELEWSKI, S. A. Cuiabá na década de 80: vestígios da matemática moderna nas quatro primeiras séries do $1^{\circ}$ grau. Diálogo Educacional, Curitiba, v. 8, n. 25, p. 675-688, 2008.

Submetido em 01 de Junho de 2020. Aprovado em 26 de Outubro de 2020. 